\title{
THE GROWTH OF BONE AUTOGRAFTS IN RABBIT EAR CHAMBERS
}

\author{
H. E. Ezra-Cohn, Philadelphia, United States of America \\ Peter G. Bullough, New York, United States of America \\ and J. Trueta, Barcelona, Spain \\ From the Nuffield Orthopaedic Centre, Oxford, England
}

Recently the transplantation of bone has stimulated much clinical and experimental research, and in vitro and in vivo studies have been reported (Chase and Herndon 1955, Goldhaber 1960, 1961, Vaes and Nichols 1962, Ray and Sabet 1963, Deleu and Trueta 1965). In this report we will demonstrate that when autogenous bone from a spinous process is transplanted into a regenerative type of ear chamber in a rabbit it survives and exhibits both new bone deposition and bone resorption. The advantages of this over other culture systems will be discussed and the survival and growth of the bone will be illustrated by optical and electron microscopy.

\section{MATERIALS AND METHODS}

Half lop-eared rabbits (bred initially by crossing a full lop-eared rabbit with a Belgian hare) aged four to five months and weighing 2.5-3 kilograms were used for chamber implantation. At this age bone growth has normally ceased and the epiphyses of the long bones are closed.

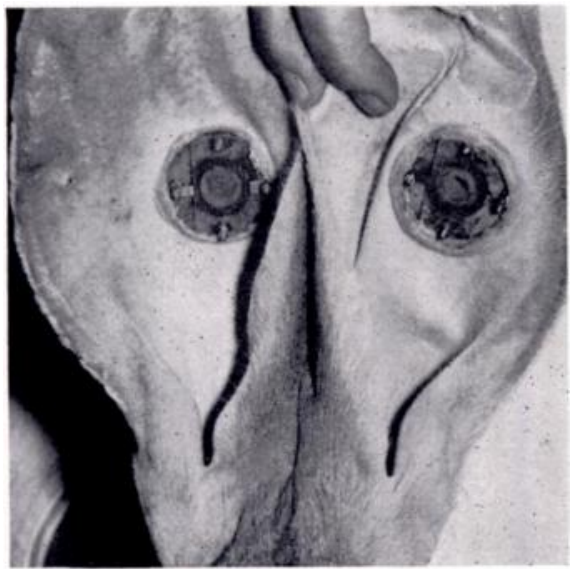

FIG. 1

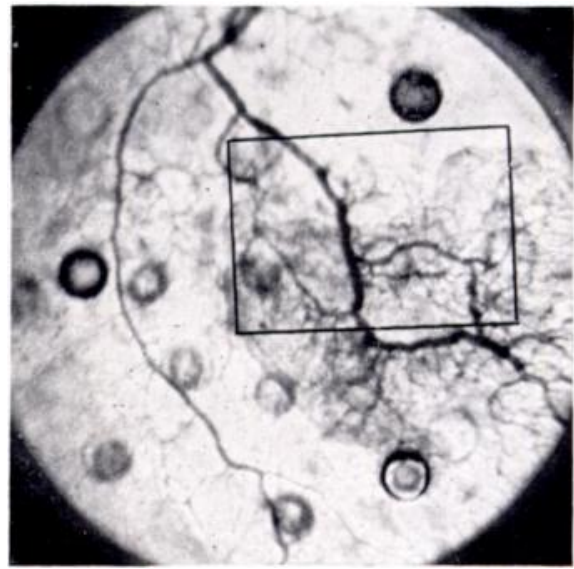

FIG. 2

Figure 1-Photograph of rabbit with chambers in situ. Figure 2-Photograph of the table of the ear chamber in situ. The outline of the bone is clearly seen. The small round holes in the cover slip are present for measuring oxygen tension in the chamber.

Transparent regenerative chambers similar to the type originally developed by Sandison (1928), Kirby-Smith (1933) and Clark and Clark (1942), but with slight modifications of our own (Ezra 1966, 1967) were implanted in the central portion of the pinna (Fig. 1).

The table of the chamber was well vascularised and ready for bone implantation in three weeks. Autogenous bone was obtained from the spinous process of the third or fourth lumbar vertebra. A fragment 0.25 to 0.5 millimetre across and with a thickness of approximately 100 microns was dissected and as quickly as possible placed in the centre of the table of the opened chamber. The chamber was closed with a sterile cover slip. The implanted bone fragment was studied microscopically every two days and its appearance recorded (Fig. 2). 


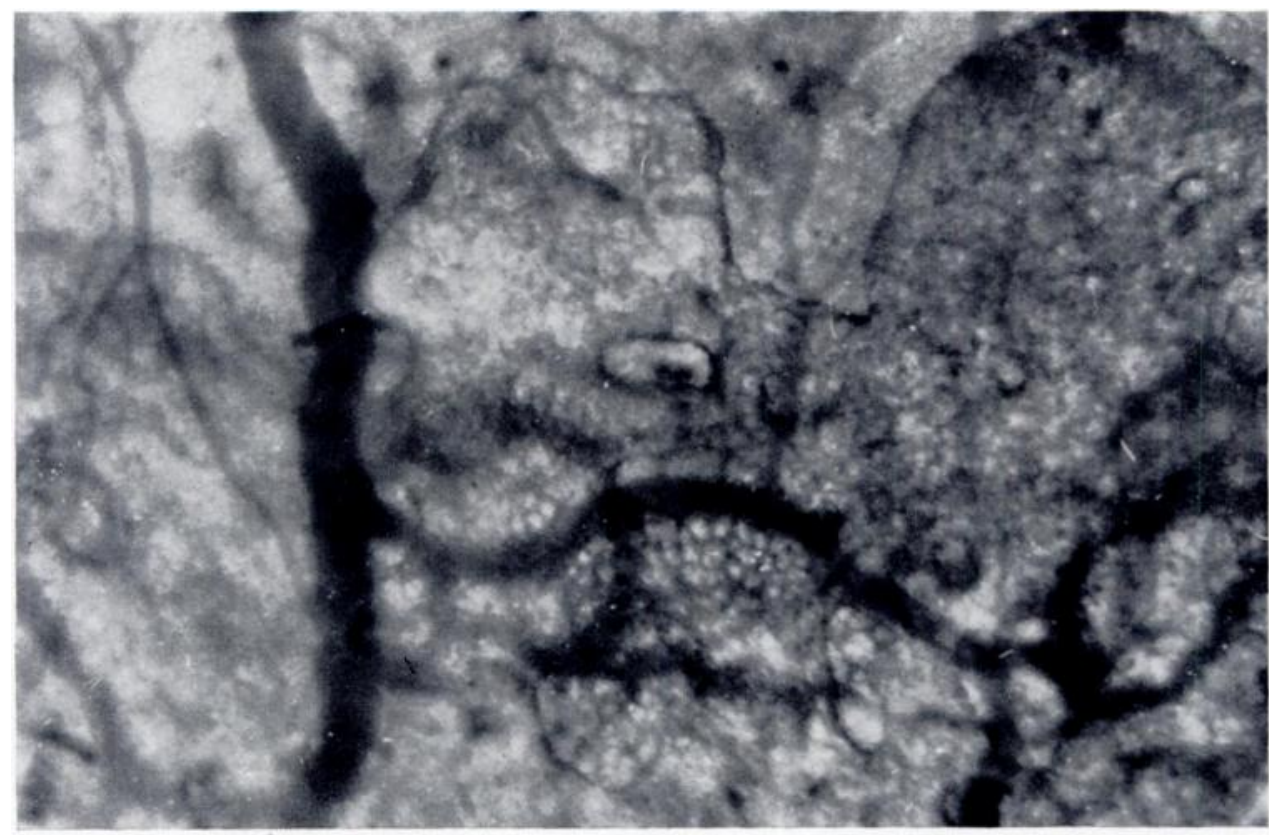

Fig. 3

Photograph of the area shown outlined in Figure 2 to demonstrate the edge of the bone graft and the holes which can be seen extending through the thickness of the bone and through which penetrating vessels are clearly visible.

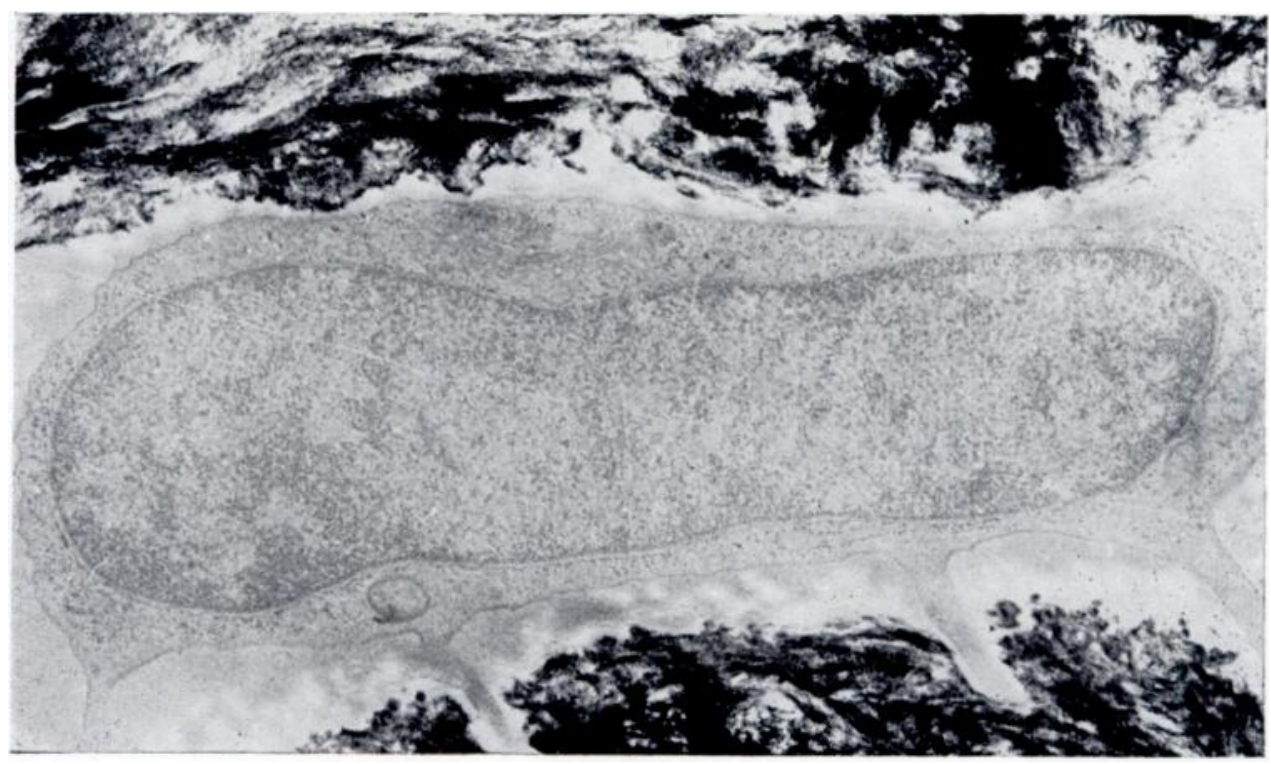

Fig. 4

Electron photomicrograph of an osteocyte from an area of lamellar bone. Note the amorphous electron-dense material around the osteoctye occupying the space between it and the bone. $(\times 10,000$. 
Twenty-five weeks after bone implantation the ear chamber while still living was perfused by intra-arterial injection with 4 per cent glutaraldehyde in $0 \cdot 1 \mathrm{M}$ cocodylate buffer. The tissue occupying the chamber was removed and placed in glutaraldehyde for a further three hours and post-fixed in 1 per cent osmium tetroxide. The tissue was cut into eight suitably mapped sections and embedded in Araldite in four flat and end-on pairs. Sections were cut with a Reichert ultra-microtome using a diamond knife and measures were taken to ensure that the bone was not decalcified. The sections were studied with a Phillips 100B electron microscope. Thick companion sections of each pair were also cut from the same blocks with a glass knife and stained with 1 per cent toluidine blue for optical microscopy.

\section{OBSERVATIONS}

The particular transplant which we have chosen to describe was chosen as representative of the seventy to 100 similar transplants studied in our laboratory. After implantation of the bone fragments it was observed that there was a reorientation of the larger blood vessels crossing the table and these came to surround the bone within seven to ten days. Branches of these vessels could be seen to course through the thickness of the bony implant so that within a short time it was enmeshed by vessels (Fig. 3). By the end of the second week it was

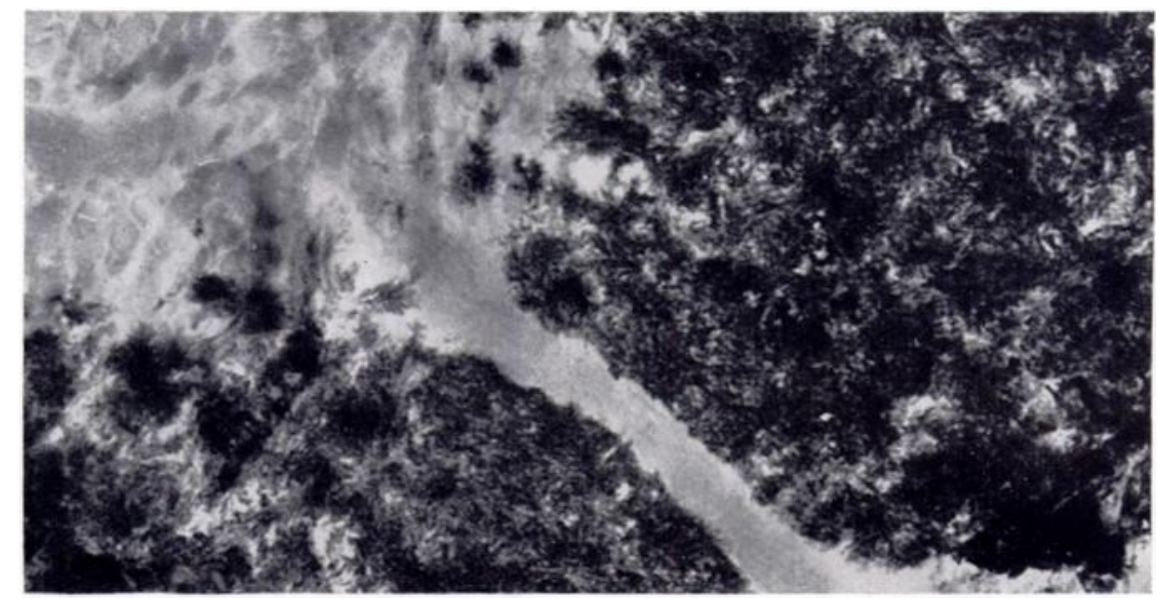

FIG. 5

Electron photomicrograph of a branching osteocyte process opening onto the exterior of the bone. $(\cdot 64,000$.)

possible to recognise plaques of new bone extending from the edge of the transplanted bone and beyond the encircling vessels. During the following weeks the size of the bone culture increased about four times.

On histological examination the table of the chamber was found to be formed of dense well orientated collagen fibre arranged in layers, with fibroblasts lying between. The surface was formed of a single layer of cells resembling histiocytes. The chamber was well vascularised but in the vicinity of the grafted bone there was an increased number of capillaries and sinusoidal channels, particularly on that surface of the bone away from the Melanex cover slip.

With regard to the graft itself, most of the osteocytic lacunae were seen to contain viable cells (Fig. 4), and intact cytoplasmic processes were demonstrable in the osteocytic cannaliculae (Fig. 5). Differences were observed, however, in the appearance of the osteocytes from area to area. Whereas many of the cells were flattened and lying in flat elongated lacunae, in some areas the cells were plump and more irregular in outline. The distribution of these two cell types accorded with the arrangement of the collagen matrix which, by both polarised light microscopy and electron microscopy, was seen to have a regular organised lamellar pattern 
in those areas where the cells were flat (Figs. 6 and 7), and a disorganised pattern where the cells were plump and irregular (Figs. 8 and 9). This agrees with the accepted description of the appearance of lamellar and non-lamellar bone respectively (Cooper, Milgram and Robinson 1966). At the surface of the bone both osteoblastic and osteoclastic activity was observed (Figs. 10 to 12). When examined by transmitted light the areas of woven bone were well distinguished from the surrounding tissue. This clear distinction was diminished when the tissue was viewed with crossed polarising filters because direct continuity of the collagen of the bone and the collagen of the surrounding fibrous tissue became evident, and this was confirmed by electron microscopy (Fig. 13).

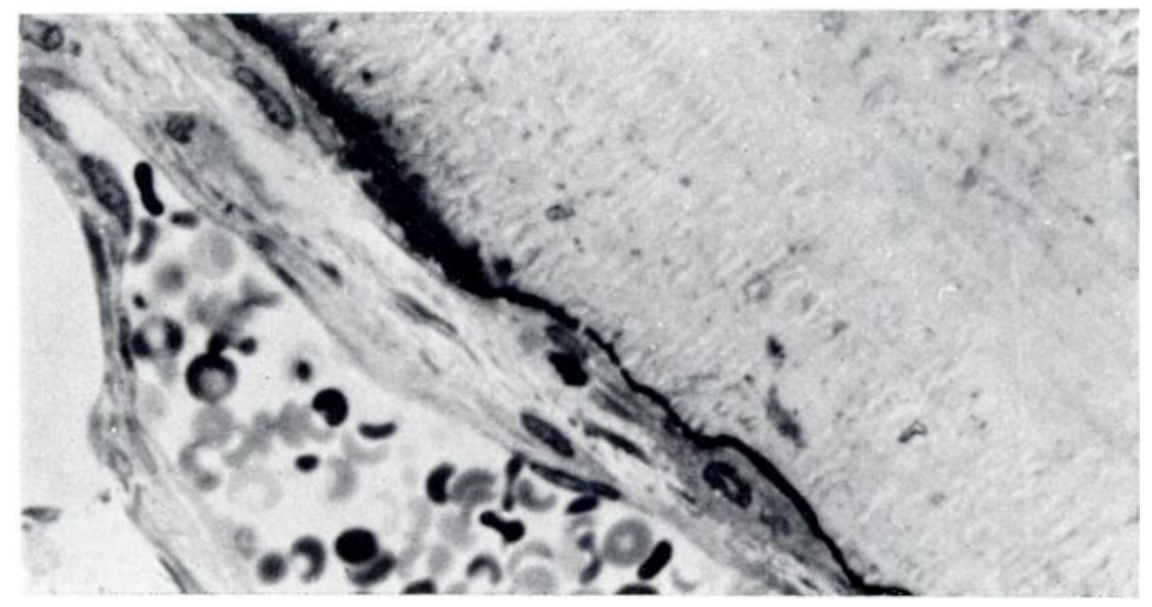

FIG. 6

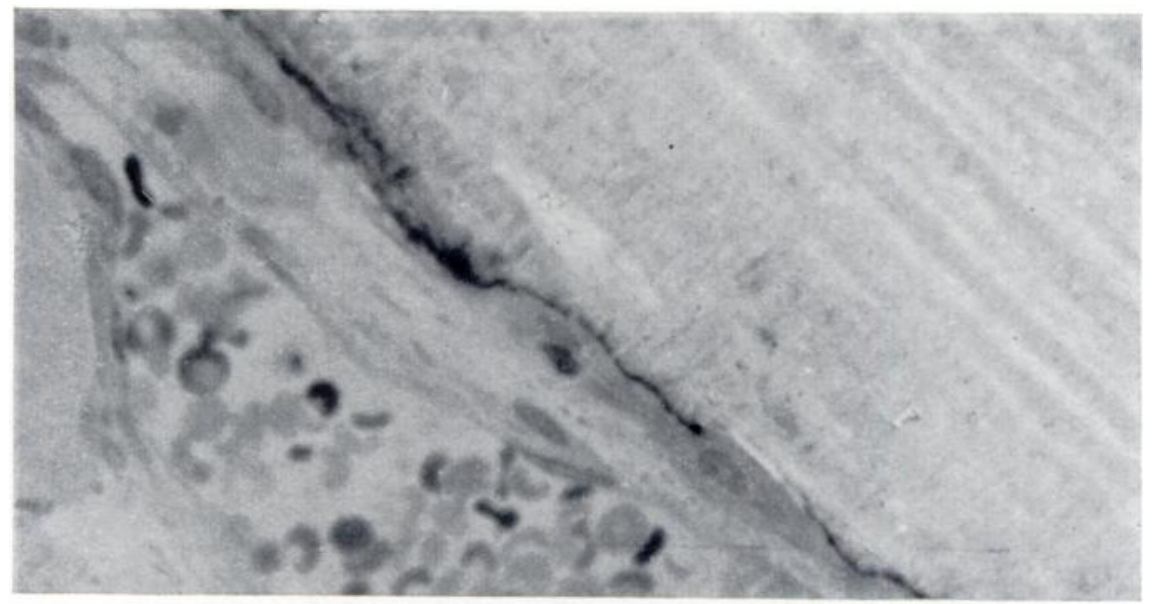

Fig. 7

Figure 6-Photomicrograph of a fragment of bone from the area of the original graft. (Toluidine blue undecalcified section, .400.) Figure 7-The lamellar structure is demonstrated in the photomicrograph taken with polarised light. (Toluidine blue undecalcified section, 400.)

\section{DISCUSSION}

The rabbit ear chamber is a remarkably convenient in vivo culture system since it permits regular observation of the activity of the transplant with little or no disturbance either to the culture or the host animal. Other in vivo culture systems such as the millipore filter chamber, the anterior chamber of the eye and subcutaneous implantations do not have these advantages. In our laboratory we used the rabbit ear chamber essentially as designed by its originators,

VOL. 51 B, NO. 2, MAY 1969 


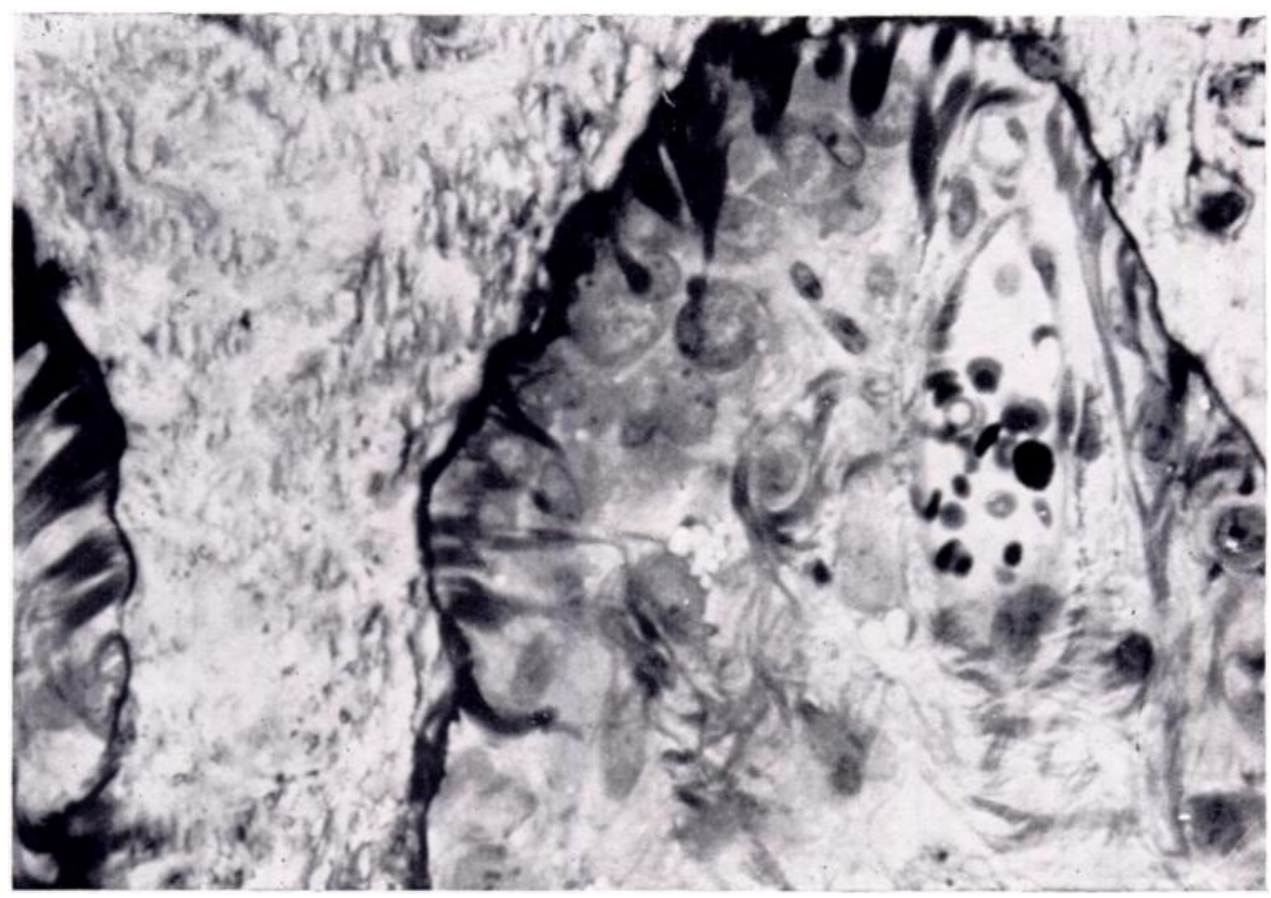

Fig. 8

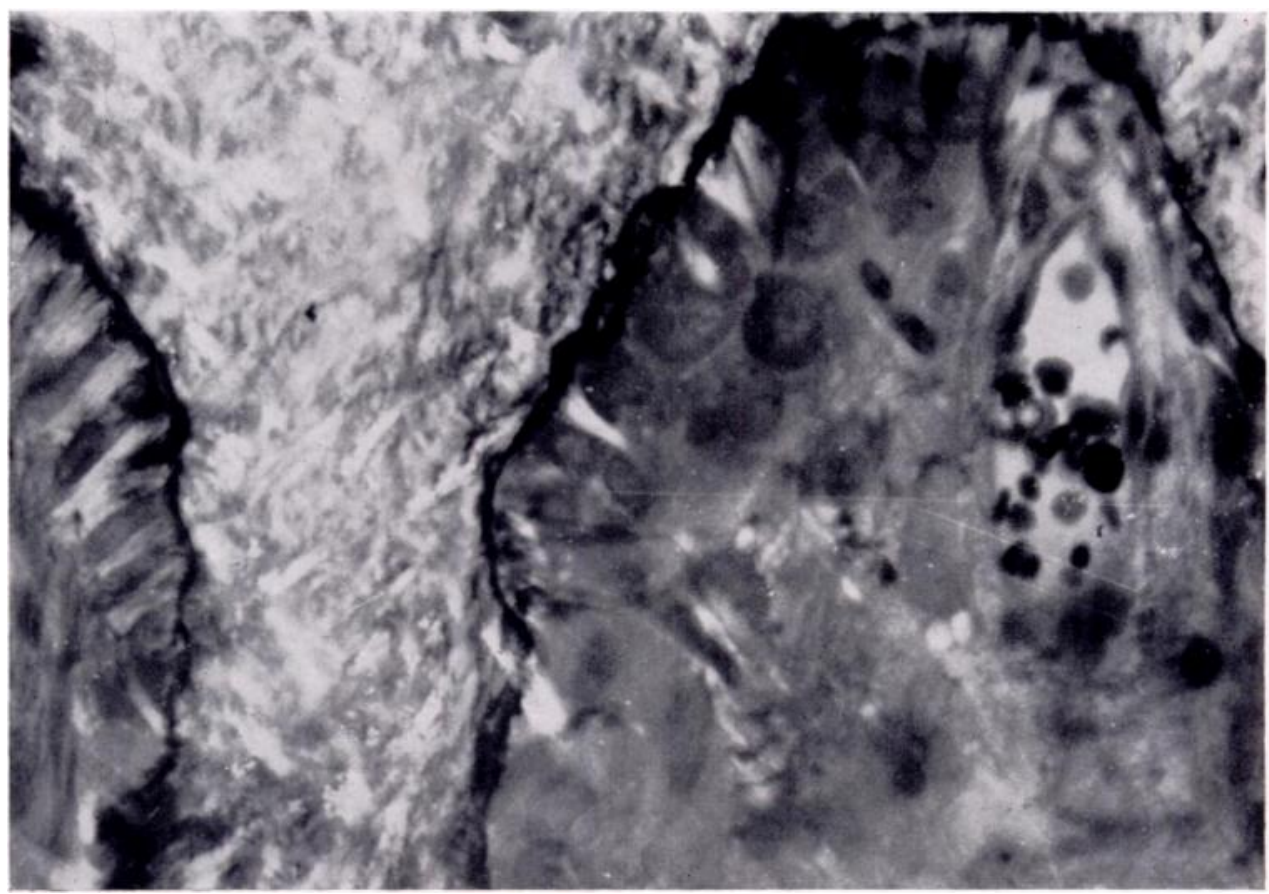

FIG. 9

Figure 8-Photomicrograph of the edge of an area of extension of the graft. Note the heavy staining at the edge of the bone and around the osteocytic lacunae and the plump cells abutting against the growing bone edge. (Toluidine blue undecalcified section, $\times 400$.) Figure $9-$ As in Figure 8 but photographed in polarised light. Note the irregular arrangement of the collagen fibres in the bone and the continuity of them with those of the surrounding tissue. 


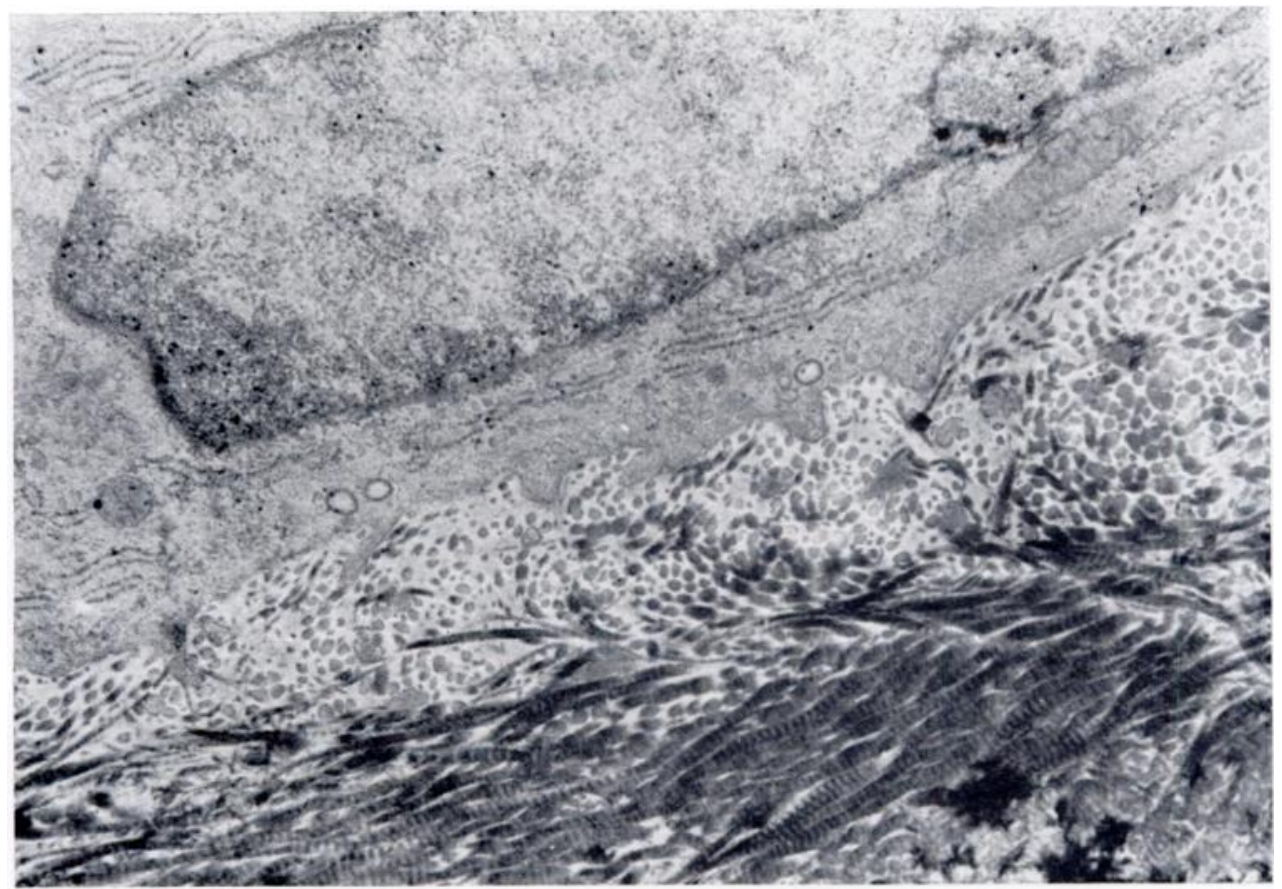

Fig. 10

Electron photomicrograph showing osteoblast with well oriented collagen and an advancing mineral front. $(\times 12,000$.

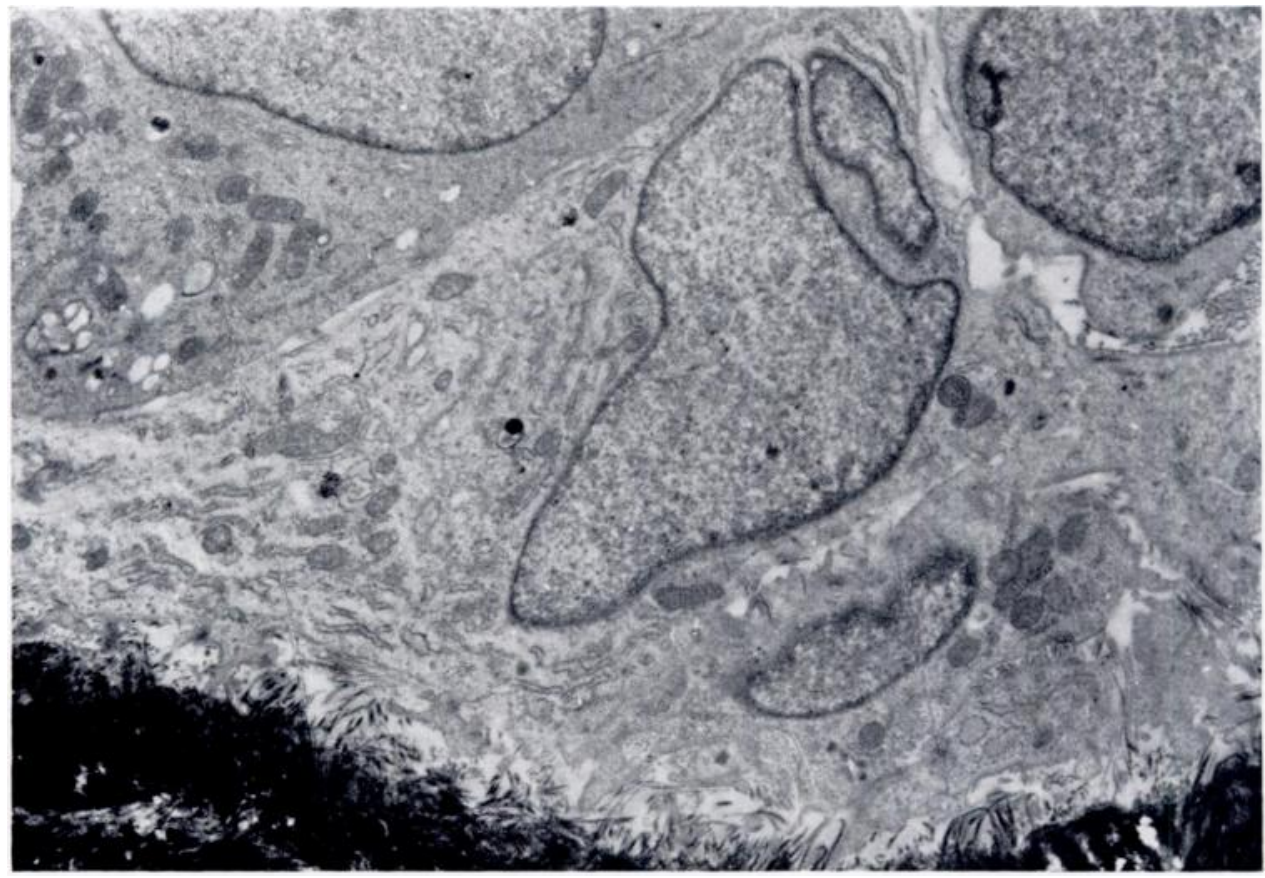

FIG. 11

Electron photomicrograph of an area of osteoclastic bone resorption. Note the quality of the brush border and the cell membrane between the cell at the upper left and that in the centre of the field. By optical microscopy these would appear as one cell. $(\times 5,250$.) 


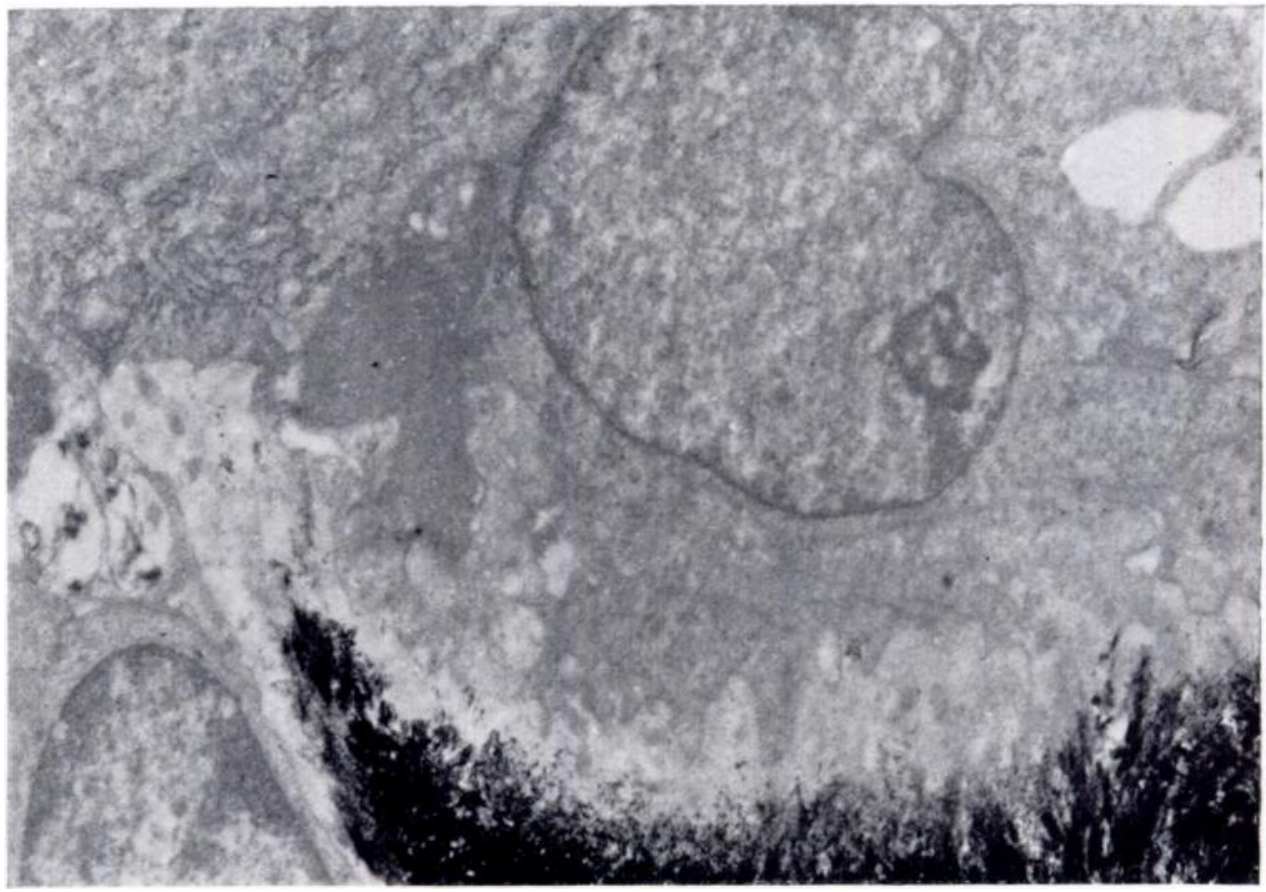

FIG. 12

Electron photomicrograph of an area of osteoclastic bone resorption showing a typical brush border and at the lower left an osteocyte being released from its bony casing. $(\cdot 12,000$.)

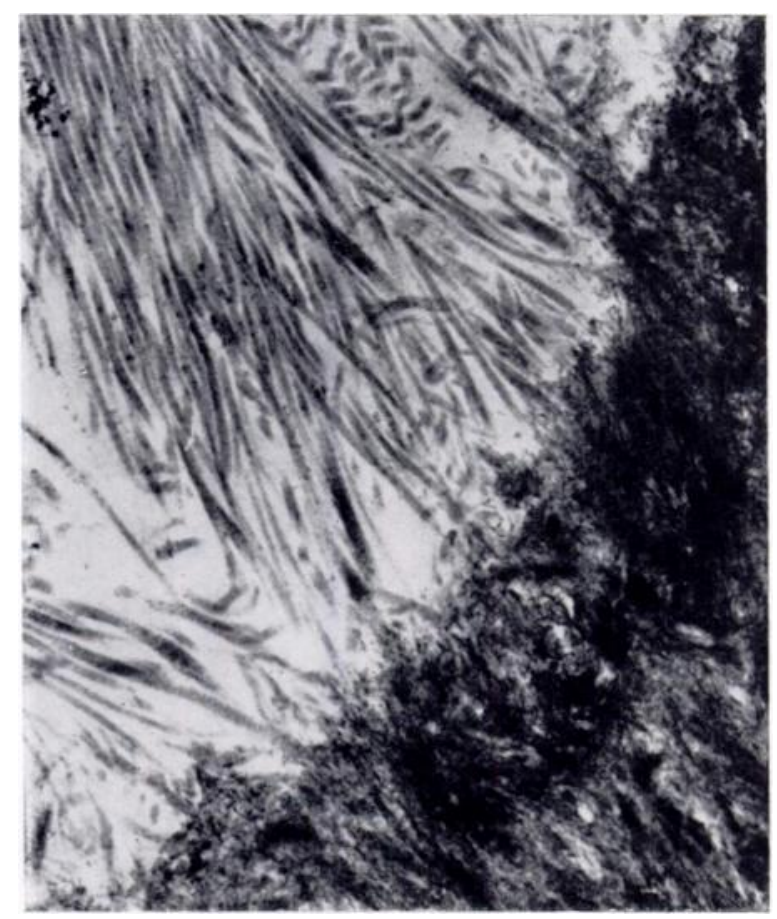

FIG. 13

Electron photomicrograph of the junction of mineralised woven bone (lower right) and bordering soft tissue (upper left). Note the continuity of the collagen fibrils and compare this with Figures 8 and 9 . (50,000.) 
Sandison, Kirby-Smith and Clark. Minor modifications were made but the only one of significance was the replacement of the glass or mica cover slip with one made of Melanex (I.C.I.). Melanex has certain properties which lend themselves admirably to this use: it is a non-wettable material and has approximately the same refractive index as glass. Cover slips were made from films of Melanex 17-25 microns thick.

Since the table of the regenerative ear chamber has a controlled volume it is possible to make precise quantitative assessments of the reactions of the culture to chemical and other agents. Direct vascular access to the vital graft is available for the introduction of a variety of agents. Immediate and continuous observation of the effects of such agents can be followed with ease. We are currently carrying on such observations.

Cooper et al. (1966) pointed out the difficulties of obtaining adequate fixation of bone for electron microscopy. However, with bone cultures in regenerative chambers we have an ideal system for rapid fixation of small cultures of organised bone.

In our experience with the regenerative ear chamber we have never found any evidence of spontaneous development of either cartilage or bone.

\section{SUMMARY}

1. A method is described for the in vivo and in vitro study of osteogenesis by implanting a modified transparent chamber in half lop-eared rabbits (as originated by Sandison 1928). This method allows the daily observation and photography of the developing bone and the study of its intimate connection with the vascularity of the area.

2. The osteogenetic potential of a variety of substances can also be investigated by this method. The tissue in the chamber can easily be prepared for its final examination by optical and electron microscopy and by other laboratory techniques.

We are grateful to Mr Peter Blackwell and to Mr David Drury for the photography. We also wish to express our appreciation to Professor R. B. Duthie for extending to us the use of facilities and staff after he assumed the Professorship of Orthopaedic Surgery, in order that this study could be completed.

This work was supported in part by the Lady Hoare Thalidomide Fund and the U.S. Army Contract: Nos. D.A.-91-591-EUC-3633 and D.A.-91-591-EUC-4048.

\section{REFERENCES}

Chase, S. W., and Herndon, C. H. (1955): The Fate of Autogenous and Homogenous Bone Grafts: A Historical Review. Journal of Bone and Joint Surgery, 37-A, 809.

Clark, E. R., and Clark, E. L. (1942): Microscopic Observations on New Formation of Cartilage and Bone in the Living Mammal. American Journal of Anatomy, 70, 167.

Cooper, R. R., Milgram, J. W., and Robinson, R. A. (1966): Morphology of the Osteon: An Electron Microscopic Study. Journal of Bone and Joint Surgery, 48-A, 1239.

Deleu, J., and TruetA, J. (1965): Vascularisation of Bone Grafts in the Anterior Chamber of the Eye. Journal of Bone and Joint Surgery, 47-B, 319.

Ezra, H. C. (1966): Study of the Effects of Oxygen Tension on Osteogenesis. Annual Technical Report, United States Army.

Ezra, H. C. (1967): Study of the Effects of Oxygen Tension on Osteogenesis. Annual Technical Report, United States Army.

Goldhaber, P. (1960): Behaviour of Bone in Tissue Culture. In Calcification in Biological Sy'stems, p. 349. Edited by R. F. Sognnaes. Washington, D.C.: American Association for the Advancement of Science.

Goldhaber, P. (1961): Osteogenic Induction across Millipore Filters in vivo. Science, 133, 2065.

KIRBY-SMith, H. T. (1933): Bone Growth Studies-A Miniature Bone Fracture Observed Microscopically in a Transparent Chamber Introduced into the Rabbit's Ear. American Journal of Anatomy, 53, 377.

RAY, R. D., and SABET, T. Y. (1963): Bone Grafts: Cellular Survival Versus Induction. An Experimental Study in Mice. Journal of Bone and Joint Surgery, 45-A, 337.

Sandison, J. C. (1928): A Method for the Microscopic Study of the Growth of Transplanted Bone in the Transparent Chamber of the Rabbit's Ear. Anatomical Record, 40, 41.

Vaes, G. M., and Nichols, G. (1962): Oxygen Tension and the Control of Bone Cell Metabolism. Nature, 193, 379.

VOL. 51 B, NO. 2, MAY 1969 